\title{
Monitoring and anticipating floods in France
}

\author{
Isabelle Leleu ${ }^{1, a}$, Bruno Janet ${ }^{1}$, Olivier Piotte ${ }^{1}$, Aurélie Escudier ${ }^{1}$, Céline de Saint-Aubin ${ }^{1}$, Jean-Luc Souldadié ${ }^{1}$, Isabelle \\ Rochet $^{2}$, Didier Jourdan ${ }^{3}$, Denis Paradis ${ }^{4}$ \\ ${ }^{1}$ Ministry of Ecology, Central Service for Flood Forecasting (SCHAPI), 42 avenue Coriolis, 31057 Toulouse Cedex 1, France \\ ${ }^{2}$ Ministry of Ecology, DEAL, 2 rue Juliette Dodu, CS 41009, 97743 Saint-Denis Cedex 9, La Réunion (France) \\ ${ }^{3}$ SHOM, 42 avenue Coriolis, 31057 Toulouse Cedex 1, France \\ ${ }^{4}$ Meteo France, 42 avenue Coriolis, 31057 Toulouse Cedex 1, France
}

\begin{abstract}
The State flood warning and anticipation tools in France have evolve a lot since the years 2000. This paper first presents an overview of the progress made since then. A description of the existing flood vigilance system ( www.vigicrues.gouv.fr ) is given, with a focus on two of the main on-going improvements: the particular case of river sections under sea influence and the specific organization dedicated to some of the French overseas territories. The next step is to underline the most recent developments carried out to extend the services offered to the public: better communication on occurring floods, forecasts and uncertainties; anticipation of flooded areas; enhanced flash flood warnings dedicated to municipalities; experiments and advice to local authorities on more direct on-site warning systems. The targeted objective is to develop tools and methods to deliver more relevant information, as responsive as possible to the different types of flooding which people are exposed to, over the whole French territory.
\end{abstract}

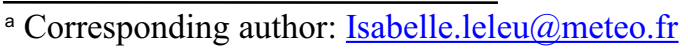




\section{Progress made in the field of flood anticipation}

The French State has gradually deeply modernized and strengthened its watching, warning and forecasting systems.

\subsection{The context}

After the severe storms of late 1999 and a number of dramatic flood events in the 1980's and 1990's in France, the general meteorological vigilance system for severe weather was implemented in October 2001 by MeteoFrance (cf. http://vigilance.meteofrance.com/). The general principle was to provide the public with simple weather-related risk information, based on a scale of four colours (green, yellow, orange and red), ranging from no risk to high risk. This system has been gradually enriched and the founding principles also extended to many European countries (see http://www.meteoalarm.eu/).

At the same time, a substantial work of reform was carried out in France in the field of flood warning systems. In the framework of a new law on risks in 2003 [1], the flood warning system reform enabled the 54 standalone flood warning services to be transformed into 22 flood forecasting centres, coordinated by a central support structure. The objectives were multiple: give to every new local flood forecasting centre, the responsibility of a more coherent set of rivers; extend the use of hydrological modelling to deliver flood forecasts; and implement a central technical and scientific service to support these local services. SCHAPI (the central hydrometeorological service in support to flood forecasting), was then created in June 2003 under the Ministry in charge of ecology and sustainable development. This new structure is located in Toulouse, near the national forecasting centre of Meteo-France). Its first task was to set up a flood vigilance system, following the same principles as the existing meteorological vigilance system.

\subsection{The flood vigilance procedure}

The flood vigilance system was launched in July 2006 , covering about $20,000 \mathrm{~km}$ of rivers monitored by the State services (among 120,000 km of rivers of more than one meter wide in metropolitan France). The concerned rivers were set out in the regulations through the flood vigilance procedure, which allows informing simultaneously the local authorities (Prefects and Mayors), civil security and emergency services, the media and the public, on the level of flood risk. In particular, this information is published on the "Vigicrues" website (http://www. vigicrues.gouv.fr).

The homepage of this website presents a map of metropolitan France with an indication of the level of hydrological risk on the main rivers. Every river covered by the procedure is divided into sections. One colour (among green, yellow, orange or red) is given to every river section, according to the level of danger which people can be exposed to within the next 24 hours (Fig.1).

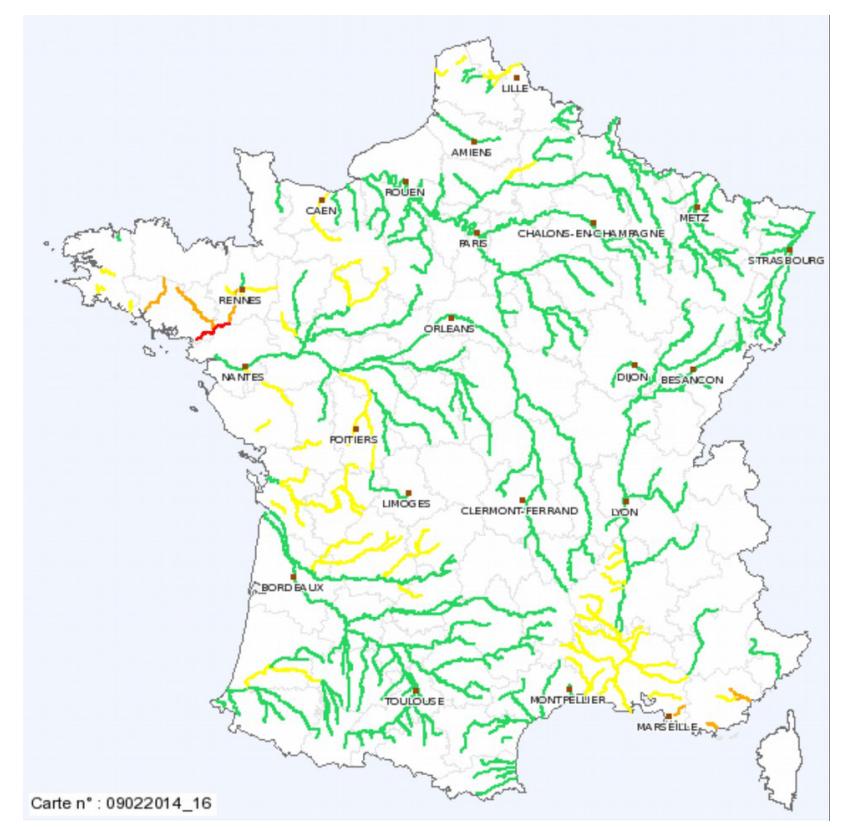

Figure 1. Flood vigilance map produced on $9 \mathrm{Feb} 2014$ at 04:00PM

The national map gives a general overview. A local view is available by clicking on the area covered by a local flood forecasting centre. Both national and local maps come with information bulletins as long as at least one river section is coloured in yellow. These bulletins give details onto the chronology, the intensity and the evolution of the floods and, when it is possible, supply graded forecasts at reference stations. Indications on the possible consequences of the flooding and advice on how to react are also given, depending on the maximum risk level; these elements have been elaborated with the Ministry of the Interior.

From the local map on the Web site, it is also possible, by clicking on a hydrological station, to get a graph or table giving the latest real time water level or flow data, as well as information on the station context.

The flood vigilance map, the bulletins and the realtime data are permanently available. The national and local maps are updated daily, at least twice a day at 10:00AM and 04:00PM (French local time), with a 24 hour valid time period. They may be updated more frequently if needed by the evolution of the flooding. The real time data are published as they become available, with a time step consistent with the kinetics of the river section.

The flood vigilance system warns the public and the authorities that there is a flood risk, with a potential severity given by the colours given to the concerned river sections. Vigilance allows the public to get ready to react in an appropriate way if the danger has to come (for example when graded forecasts confirm that the flood is likely to happen). It also helps local authorities to preposition means of assistance, take safeguard measures, and possibly launch an alert and apply a local protection plan. 


\subsection{Improvements brought in about 10 years}

Since it was set up, the flood vigilance procedure has been the subject of various strengthening and improvement actions.

In order to provide an overall view of the weatherrelated risks, the flood vigilance information was integrated into the meteorological vigilance map, through its "rainfall - flood" component (in December 2007) and its "flood (without heavy rain)" component (in October 2011). In deed, the meteorological vigilance map is now used as a unique entry point, focusing for every local area on the most severe risk for the next 24 hours.

In consultation with the Ministry of the Interior, the flood vigilance procedure has been revised in 2014 [2], to better take into account the evolutions which both Ministries knew since 2006: in particular, the consequences of the 2004 Law on civil safety modernization [3], the new version of the Flood Forecasting Master Plan in each of the 6 main administrative water basins in metropolitan France [4], and the implementation of a technical support with every Prefect for the preparation and management of flood crisis [5].

Strengthening the rainfall observation was also a key issue, which has been addressed since late 2011 through a special joint program between Meteo-France and the Ministry in charge of ecology, to modernize and extend the meteorological radar and rain gauge networks. This program is still on-going. Other important technical evolutions were made to modernize water level and flow measurements in the rivers, and to start to refund the national hydrometric database (named "Banque Hydro"), the heart of the information system for flood forecasting and hydrometry.

In parallel, according to stakes evolution and following the scientific and technical advances, significant work has been undertaken to gradually increase the kilometers of rivers monitored by State services (more than 21,000 km in 2012, 22,000 km in 2015). This increase has been made possible through the improvement and streamlining of forecasting models as part of a national strategy progressively implemented, and the extension, to more water basins, of the use of the models selected under this strategy.

Among various enhancements, the extension of the river network monitored by State services has been organized in two particular directions:

- to improve flood forecasting in river sections under sea influence in mainland France,

- and to set up a flood anticipation service in some French overseas territories.

These two development axes are detailed in the following paragraph.

\section{Two specific development axes to extend the river network monitored by State services}

\subsection{Storm surge and sea state forecasting: a crucial component for flood anticipation in areas under sea influence}

HOMONIM (in French: Historique, Observation, MOdélisation des NIveaux Marins) is a joint project between the French hydrographic and oceanographic office (SHOM) and Meteo-France, which started in 2012 for a first 3-year period. It is partly funded by the Ministry in charge of ecology in the framework of the National Plan for Rapid Flooding.

Its main objective is to improve the capability and relevance of the vigilance system operated by MeteoFrance, in front of risks of waves and coastal submersions, by the implementation of new tools to forecast coastal sea levels, storm surges and sea states. One of its indirect objectives is to provide flood forecasting models with better sea level input, for river sections under sea influence.

The first phase of the HOMONIM project (20122015) was structured in different macro-tasks, which aimed at complementing various essential components of the operational forecasting system:

- enhance tide observation capacities;

- elaborate bathymetric digital terrain models, of sufficient footprint and quality to allow building new model configurations, with resolutions adapted to each model needs ;

- develop and start operation of a new modelling string of storm surges on French mainland coasts;

- develop and start operation of a new modelling string of sea states up to the coast.

The configurations for storm surge and water level computing have been built on the core of the HYCOM model (Bleck, 2002) in its SHOM version (Baraille \& Filatoff, 1995) and in barotrop mode. Two areas have been defined for calculation: one for the Atlantic facade and one for the Mediterranean facade.

The model used for waves generation and propagation in the "waves - sea submersion" vigilance system, is the WAM model in its Meteo-France version (Lefèvre et al., 2009) on a regular $0,1^{\circ}$ grid-scale resolution. In the corresponding macro-task, the objective is to lead to a more accurate sea state modelling, by adding a coastal configuration, coupled with MF-WAM at the opened boundaries and based on the WW3 model.

This first phase of the HOMONIM project has finished in 2015. The obtained results already contribute to the "waves - sea submersion" vigilance system operated by Meteo-France. In deed, the new modelling 
string of storm surges, which has been developed within the project, started operation in January 2014 (Fig 2.).

Since then, an update of this string was made, using the bathymetric digital terrain models and other recent results produced by the project, to further improve the model.

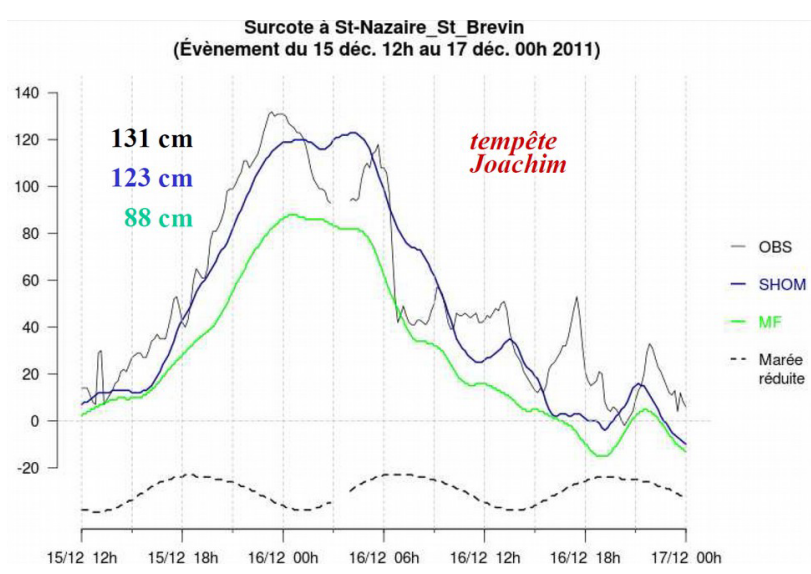

Figure 2. Improved storm surge and sea level forecasts obtained using the HYCOM model (SHOM version), compared to the output of the modelling system used before 2014.

Case study of storm Joachim (December 2011)

Then, the new modelling string for wave prediction started running in early 2015 . It complements the existing system with more accurate information for the forecasters responsible for the "waves - sea submersion" vigilance production.

Beyond, work continued on coupling HYCOM and WW3 models, with the consideration of sea states in HYCOM and that of water levels and currents in WW3. This work was carried out on a demonstration area (Perthuis charentais), for which a $2 \mathrm{D}$ high resolution configuration was set up by successive fittings. This study allowed confirming the technical feasibility of such a coupled system.

The second phase of the project just started in 2015 for another 5-year period. The objectives are:

- $\quad$ to enhance the performance of the "waves - sea submersion" vigilance system in mainland France, with a capacity de develop coupled high resolution modelling in specifically exposed areas;

- to improve the existing sea level anticipation capabilities in overseas territories, in particular to address the need for a "waves - sea submersion" vigilance system in these territories;

- to take advantage of the improved sea hazard forecasting in the cooperation with other actors.

This last item will specifically deal with using results from the HOMONIM project as an input to the existing flood forecasting tools, in order to improve flood anticipation for river sections under sea influence.

\subsection{Flood anticipation in Corsica and French overseas territories}

The existing flood vigilance procedure was designed for water basins located in metropolitan France. Corsica and the French overseas territories have specific characteristics in terms of configuration and kinetics of water basins, but also in terms of observation means, administrative organization and local context. Thus, the flood anticipation procedures that are implemented may differ from those deployed in metropolitan France, in order to take into account the specificities of each territory and to offer to the public a service which is adapted to the local context.

For this reason, the State services in charge of flood anticipation there, are not called "Flood Forecasting Centre" as in mainland France, but "Hydrological Monitoring Unit", reflecting the significant challenge to achieve real forecasting services.

The work to establish such Hydrological Monitoring Units (HMU) in Corsica and French overseas territories is well advanced. Three HMU provide today operational productions, in La Reunion (Indian Ocean) since March 2013, in Corsica since November 2014 and in French Guyana since April 2015.

In La Reunion, the deployed system is based on a flood vigilance map, following the same principles as those used in mainland France, with four colours corresponding to four risk levels, one colour being assigned to a whole water basin instead of a river section, given the reactivity of the monitored basins in La Reunion and the fact that dry gullies can be quickly full of water during heavy rain events. 17 water basins are monitored today in La Reunion by the local State HMU, with a vigilance map being produced as soon as there is a flood risk (Fig. 3).

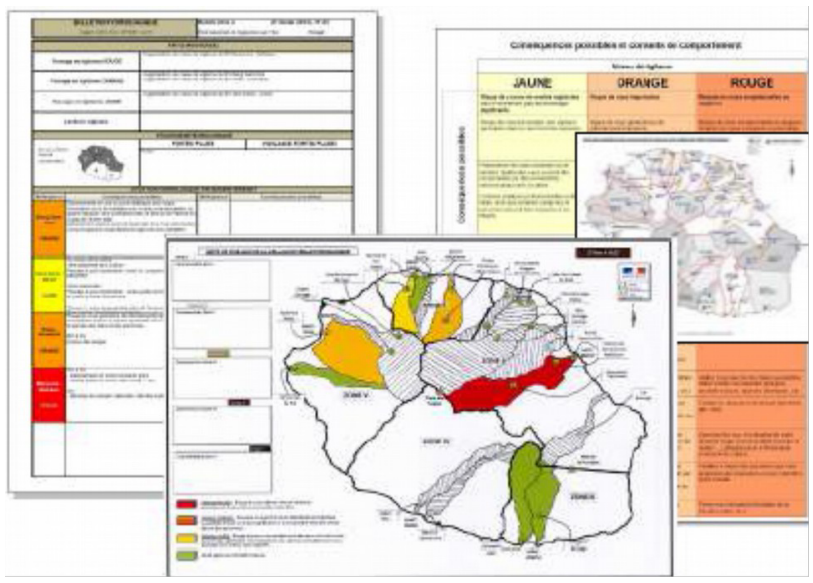

Figure 3. The flood vigilance system in La Réunion (France)

In Corsica, the water basins characteristics do not allow producing real time flood vigilance information, given the observation means that are available today. Nevertheless, the observed data on the 6 most exposed water basins have enabled since November 2014 to calculate, twice a day on each of these basins, a hydrological sensitivity index for the next 48 hours. 
The local context is much different in French Guyana where the most exposed stakes are located near the big Maroni River, on the western boundary of the country. During the wet season, the Guyana HMU delivers since 2015 flood vigilance information for 4 sections in the median part of the Maroni River, in a very similar way as what is implemented in mainland France. The specificity of this HMU lies in the fact that it also delivers, during the dry season, information on the risk of low water for the downstream parts of 3 rivers: Maroni, Kourou and Comté.

Beyond, work is underway since 2013 for the set up of HMU in the West Indies (Martinique and Guadeloupe) and a prospective mission was also carried out in Mayotte (Indian Ocean) in 2015 for this purpose.

\section{Further innovative developments}

All these gradual improvements and progress since 2006 were crucial to strengthen the existing State flood vigilance and forecasting system, allowing an opening to deeper evolutions. In particular, further innovative studies started near the 2010's in different directions.

\subsection{Under the banner of a new brand}

In order to increase the scope of the flood vigilance information and forecasts provided by the State services, and to make the ministry in charge of ecology more visible on these issues for the public, all products delivered in this field by the State departments are now together under a new brand, launched in February 2015:

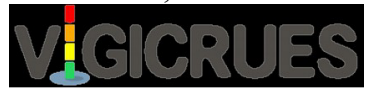

This new brand offers a sign easily recognizable by the public for the information delivered in real time during flood events, and using it on various communication vectors will also allow maintaining the risk culture among the citizens.

\subsection{A website dedicated to high water marks}

The flood location pins, and more generally any high water marks (Fig. 4), including leashes, testimonies and photographs, provide valuable data for many actors involved in risk prevention, risk culture, hydraulic studies, flood mapping or the planning of waterways or coastal areas.

The Flood Forecasting and Hydrometry Network (which gathers SCHAPI and the local flood forecasting centres and hydrometry units in State departments), has launched a major initiative aiming at providing a repository, an organization and tools to move towards nationwide collaborative management of high water marks.

The work carried out includes:

- $\quad$ building a repository and a national database which aims at bringing together all existing inventories of high water marks and flood leashes;

- creating a collaborative and cartographic website allowing consulting, contribution, publication and data management by the various involved actors, at their respective levels.

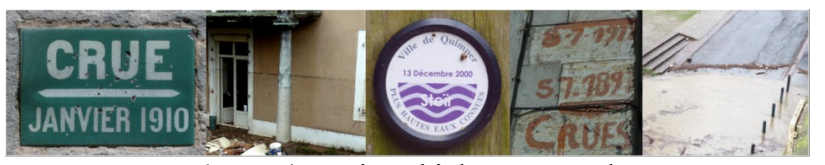

Figure 4. Various high water marks

After the development of the database and the associated website, and an important work to integrate data from existing deposits of flood marks and leashes, the national high water mark website will open in 2016.

\subsection{View forecasts and associated uncertainties}

Real-time information on flooding is a key element of decision support for crisis management, for the State services as for local authorities or individuals. A graphical access to water level or flow forecasts, produced by the local flood forecasting Centres (SPC) and coordinated by the Central Service for Hydrometeorology and Support to Flood Forecasting (SCHAPI), is very much expected by all the actors listed above.

In 2016 , this type of publication will be widespread on the national Vigicrues website, where it will now be possible to display the water level and flow forecasts on station graphs, in line with the observed data (previously already available).

Forecasts are inherently uncertain. To provide the actors with useful information on the different scenarios that are likely to happen, forecasts will be represented by three "trends" (3 values for every time range, see Fig.5):

- a low trend, representing a scenario which is likely to be exceeded ( $90 \%$ chance of being exceeded);

- a median trend, representing a "central" scenario ( $50 \%$ chance of being exceeded);

- a high trend, representing a scenario unlikely to be exceeded ( $10 \%$ chance of being exceeded).

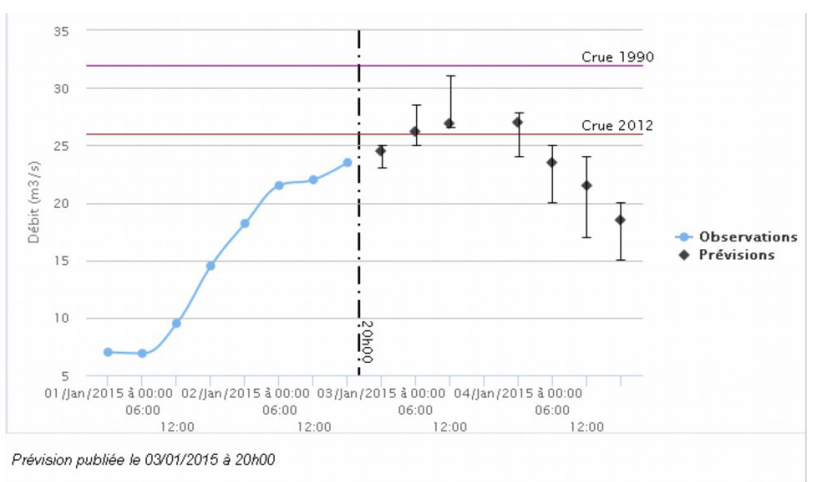

Figure 5. Graph with forecasts and associated uncertainties, represented by three "trends" for every time range, in line with observed data on Vigicrues website (forecasts in black). 
For each river section where a forecasting model has been calibrated and is operational, forecasts and associated uncertainties are now produced on some points of the river section, and will soon be published on the Vigicrues website, provided the model simulates the river behaviour with enough realism and that the forecaster concerned can criticize the model forecasts and assess a confidence degree in its own forecasting.

\subsection{Flooded area forecasting}

Data on potentially flooded areas are useful to crisis managers, from national to local level, in particular to evaluate the human and material resources to be mobilized before and during a flood event. The Flood Forecasting and Hydrometry Network aims at complementing the vigilance and flood forecasting information, published on the www.vigicrues.gouv. $f r$ website, with information on the areas likely to be flooded.

To make such data easily accessible, a database called "VIGInond" has been developed to store sets of maps of potential flooded areas corresponding to different water levels at reference hydrometric measurement stations (Fig. 6). In real time, as soon as water level forecasts are published at these reference stations, the corresponding maps in the VIGInond database can be used to figure out the outline of the areas likely to be flooded.

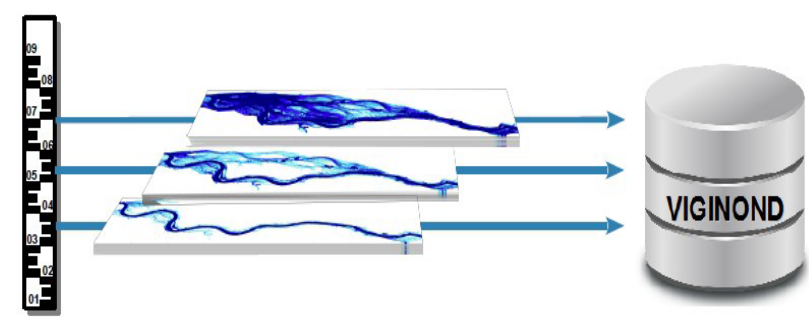

Figure 6. Constitution of potential flooded area maps sets, corresponding to different water levels at reference hydrometric measurement stations, which will then be used in forecasting.

This national database, coming with associated cartographic web services, was made operational in May 2015 (Fig. 6). The dissemination of information on potential flooded areas, first within the Ministry, allows testing the service and informing each actor on the potential impacts of predicted floods.

After this testing phase, planned for 2016 and 2017 with a group of chosen actors, the delivery will be extended to other crisis managers and perhaps to the public. The gradual implementation of products on potential flooded areas will better educate every actor or citizen exposed to flood risk.

\subsection{A new flash flood warning service}

The French State services in charge of flood forecasting monitor 22,000 $\mathrm{km}$ of rivers (among the $120,000 \mathrm{~km}$ of rivers over 1 meter wide in the country). $75 \%$ of the population exposed to flood risk can receive and take benefit from the flood vigilance information.

The need arose to quickly provide innovative answers to anticipate violent and sudden floods affecting some basins reacting in very short time. Thus, the concept of an automatic flash flood warning service dedicated to local crisis managers emerged.

This new service is based on a hydrological rainfallrunoff modelling system (developed by IRSTEA on all the rivers of France), fed in real-time by quantitative estimates of current precipitation (rainfall amount derived from radar imagery, provided by Meteo-France). Every quarter of an hour, the hydrological model considers the flow rates on rivers that are eligible to this warning service, and compares them to two chosen thresholds corresponding to a potentially high or very high flood risk for this river basin.

We assess then which municipalities will be affected by threshold overruns. If these municipalities are already subscribed to the flash flood warning service (the subscription is free of charge), they will be automatically notified by vocal message, and possibly by sms or email. When a warning is received, the target municipality is encouraged to check the dedicated web interface, which allows displaying a map of the notified municipalities and the rivers concerned.

This flash flood warning service is expected to open late 2016 - early 2017.

\subsection{Further exploration fields to help communities}

In areas exposed to flood risk and where the system set up by the State services is not adequate (very short reaction time or enormous cost/stakes rate), other actions are carried out as to help, even incite, developing local warning systems and setting up, with the concerned authorities, the organisation of the coherence of these devices with those of the State. The support in this case may take various forms (advice, technical assistance, exchange of observed or predicted data...), depending on expressed needs, technical skills of the concerned community, State resource availability...

In this context, an experiment of local warning devices is planned in a tropical environment with the State Hydrological Monitoring Unit in La Reunion, and guidelines are being prepared to assist communities to deploy such systems. This experiment will take place in the coming months; it will enable to offer a local and autonomous solution to communities in the French island territories which have stakes exposed to flood risk with highly reactive watersheds. 


\section{Conclusions}

Since the establishment of the Flood Forecasting and Hydrometry Network between 2002 and 2005 and the launch of the flood vigilance procedure in July 2006, much progress has been made, consolidating the existing procedure, extending the monitored hydrographical network, and opening the way to a more innovative and better targeted offer to the public.

In a context of climate change where flood events could be more frequent and / or more severe in the future, it is indeed crucial for the French State to provide users with information on planned floods, as relevant and as adapted as possible to the different configurations of watersheds and to the various contexts encountered on the whole French territory.

\section{References}

[1] Loi n²003-699 du 30 juillet 2003 relative à la prévention des risques technologiques et naturels et à la réparation des dommages.

[2] Circulaire interministérielle du 11 juin 2014 relative à la procédure de vigilance « crues »

[3] Loi n ${ }^{\circ}$ 2004-811 du 13 août 2004 de modernisation de la sécurité civile.

[4] Circulaire ministérielle du 4 novembre 2010 relative à l'organisation de la prévision des crues et de l'hydrométrie

[5] Circulaire interministérielle du 28 avril 2011 relative à la définition et à l'organisation au sein de la direction départementale des territoires (et de la mer) de la mission de référent départemental pour l'appui technique à la préparation et à la gestion des crises d'inondation dans les départements couverts par un service de prévision des crues. 